\title{
$\mathrm{PH} \mathbf{9 8}$ articulos
}

\section{Los bienes comunales y el patrimonio como estrategia frente a la despoblación. Una mirada desde el mundo masovero}

Luis del Romero Renau | Departament de Geografía i Institut Interuniversitari de Desenvolupament Local, Universitat de València

URL de la contribución <www.iaph.es/revistaph/index.php/revistaph/article/view/4513>

\section{RESUMEN}

Los bienes comunales como conjunto de espacios y tradiciones propias de las comunidades rurales han sido fundamentales a lo largo de la historia en su organización y reproducción social. Las dinámicas de despoblación que ha experimentado la España rural desde hace más de un siglo han ido en paralelo con la decadencia y desarticulación de este tipo de bienes. El objetivo de este trabajo es analizar la importancia de los bienes comunales en el medio rural, y particularmente en la construcción y producción de diferentes espacios, hoy en día patrimonializados por su importancia histórica, cultural o religiosa. En segundo lugar, se pretende mostrar que los bienes comunales, además de ser formas de relación social del pasado, pueden ser herramientas útiles en cualquier estrategia de revitalización de espacios rurales en declive, sobre todo a partir de la puesta en marcha de proyectos de custodia patrimonial colectiva en antiguas propiedades del común hoy en día en desuso o abandonadas.

\section{Palabras clave}

Bienes comunales | Despoblación | Patrimonio rural | Teruel | 


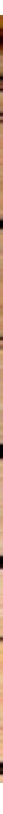

Communal goods and heritage as a strategy against depopulation. A look from the masovero world

\section{ABSTRACT}

The communal goods as a set of spaces and traditions typical of rural communities have been fundamental throughout history in the organization and social reproduction of these communities. The depopulation dynamics that rural Spain has experienced for more than a century have gone hand in hand with the decay and disarticulation of this type of goods. The objective of this work is to analyze the importance of communal property in rural areas, and particularly in the construction and production of different spaces, nowadays protected for their historical, cultural or religious importance. Secondly, it is intended to show that communal assets, in addition to being forms of social relationship of the past, can be useful tools in any revitalization strategy of declining rural spaces, especially since the implementation of custody projects collective heritage, in old common property now in disuse or abandoned.

\section{Key words}

Communal goods | Depopulation | Rural Heritage |Teruel |

Cómo citar: ROMERO RENAU, L. (DEL) (2019) Los bienes comunales y el patrimonio como estrategia frente a la despoblación. Una mirada desde el mundo masovero. Revista PH [en línea], n. ${ }^{\circ}$ 98, octubre 2019, pp. 88-106 <www.iaph.es/revistaph/index.php/revistaph/article/view/4513> 


\title{
LA DESPOBLACIÓN COMO PROBLEMA DE ESTADO
}

\begin{abstract}
"Esta villa y su común tiene los propios siguientes, una casa de Ayuntamiento, y contigua a ella otra que sirbe para carnezería y taberna, un horno, un mesón, dos corrales que sirben para zerrar ganado, una fragua que sirbe para adobar las rejas de la labor, un granero en la plazuela, una dehesa boyal poblada de matorrales a la que se regula su producto por su pasto y leña, otra llamada la Maña poblada de sabinos y robres, un monte carrascal, otro monte rebollar..."
\end{abstract}

Extracto del Catastro de Ensenada para el municipio de Ciria (Soria). Ministerio de Cultura (2017)

Los bienes comunales como conjunto de espacios y tradiciones de gestión basadas en la comunidad han sido fundamentales a lo largo de la historia para la organización y reproducción social de estas comunidades. En el caso de Aragón, Valencia y Catalunya, los bienes comunales revistieron especial importancia en el mundo masovero o del hábitat disperso de montaña mediterránea. Su decadencia ha ido en paralelo con las dinámicas de despoblación que han experimentado numerosas áreas rurales desde hace más de un siglo. Sin embargo el interés académico y político en los últimos siglos se ha centrado más genéricamente en el fenómeno de la despoblación que en una de sus causas principales: la crisis y desmantelamiento de los bienes comunales. La preocupación por la despoblación de la Península ha sido en definitiva un lugar común en la historia política española, con episodios especialmente trágicos como la expulsión de los moriscos en 1609 o las guerras y pestes en ese mismo siglo (CERVERA, 2019), que llevaría en el siglo XVIII a los intentos de colonización de Sierra Morena. Más modernamente, y especialmente tras el desastre del 98, esta preocupación pasó a ser considerada uno de los múltiples males que estaban detrás de la larga decadencia del país. Como refiere Sergio Campos, en 1899 se publicó El pauperismo en Álava. Inmigración a la capital: medios de combatirla, de Eulogio Serdán y Aguirregaviria, y en 1926, Gravísimo problema nacional, al engrandecer las ciudades se ayuda a la despoblación de los campos y se fomenta la pobreza y la miseria del país, de Emilio Zurano Muñoz (CAMPOS CACHO, 2018).

La recién inaugurada dictadura franquista se esforzó durante años en intentar asentar población en el medio rural a través de dos todopoderosos organismos: el Servicio Nacional del Trigo (SNT) y el Instituto Nacional de Colonización (INC), a los que se dotó de abundantes recursos y competencias, y cuya existencia coincidió, casi exactamente, con la del régimen (GÓMEZ BENITO, 2004). Entre 1940 y 1959 hubo una política agraria incentivadora del aumento de la producción y de la ruralización de la sociedad española con una compleja relación entre modernidad y tradición (GÓMEZ BENITO, 2004; ALARES LÓPEZ, 2010). No obstante, también se produjo en esta época la mayor crisis demográfica moderna del medio rural español de 
la edad contemporánea (GÓMEZ BENITO, 2004: 17), motivada por un hundimiento de la agricultura y ganadería tradicionales, así como por la puesta en marcha de una serie de políticas de estado que incentivaron el vaciamiento demográfico del agro español, desde políticas hidráulicas, a forestales, fiscales o de servicios (DEL ROMERO RENAU, 2018).

Con la recuperación de la democracia y el nuevo Estado de las Autonomías, la despoblación rural fue una preocupación política y académica secundaria, puesto que los flujos de éxodo rural comenzaron a disminuir de manera palpable en la década de los ochenta. Se consolidó en cambio una cierta sensibilización frente a la pérdida patrimonial, de identidad, e incluso ambiental que suponía el abandono de pueblos (LÓPEZ PALOMEQUE; FELIP FILLAT; TULLA et ál., 1996; MONTSERRAT; VILLAR, 1999; ACÍN FANLO, 2003), lo que motivó el desarrollo de las primeras políticas rurales para evitar el éxodo rural, aunque solamente en unos pocos casos como Catalunya, o Aragón en menor medida, políticas que se ampliaron posteriormente con la integración europea de la mano de programas como el LEADER.

Tras el leve repunte demográfico que vivieron algunas áreas rurales durante los años del boom económico del ladrillo y del turismo rural, no ha sido hasta hace relativamente pocos años que la despoblación ha vuelto a situarse en la agenda política a nivel autonómico y nacional. Este fenómeno ha ido cobrando creciente importancia mediática, sobre todo gracias a la publicación de ensayos y crónicas sobre sus impactos, principalmente por parte de periodistas, donde de nuevo el abandono del patrimonio y de una memoria colectiva tienen un especial énfasis. Algunos autores como Gancedo (2015), López Andrada (2017), Del Molino (2016), Badal (2018) o la crónica escrita por Cerdà (2017) sobre los últimos pueblos habitados del Sistema Ibérico dan buena cuenta, desde el ámbito periodístico, de la magnitud del desastre. Estos trabajos son en su mayor parte descriptivos y se mueven en el terreno de la nostalgia sobre tal y cual oficio que se pierde, pueblo que se cierra o escuela que deja de tener niños. No obstante, esta generación de escritores consiguió el importante mérito de introducir en el debate público y mediático un problema que sin embargo llevaba décadas presente y sin prácticamente atención.

En el terreno académico también se han publicado trabajos de gran importancia, y como siempre de menor repercusión mediática, sobre el fenómeno de la despoblación, entrando a analizar con más detalle las causas profundas que explican este fenómeno. Destacan en este sentido los trabajos de García Martínez (2016), desde el campo de la antropología y denunciando la pérdida cultural que supone el declive demográfico, así como Collantes Gutiérrez (2004) desde el ámbito de la economía, con su trabajo sobre las causas históricas del éxodo rural de la montaña española. Desde la geografía francesa y británica, también existen referencias fundamentales como 
1

Ver en este mismo número pp. 172-183
Perrier-Cornet (2003) o Marsden (1995), que trabajan sobre las mutaciones en cuanto a funciones que ha experimentado el medio rural en las últimas décadas.

En la actualidad la despoblación es una preocupación social y política, aunque hasta la fecha no se ha substanciado en ninguna política o plan concreto a nivel estatal. Muchas de las reivindicaciones de movimientos sociales como Teruel Existe ${ }^{1}$, Soria Ya o La Otra Guadalajara, recogidas por la Comisionada frente al reto demográfico y diversos gobiernos autonómicos, parecen centrarse básicamente en el ámbito de la financiación autonómica y en el de la provisión de infraestructuras como estrategias básicas de revitalización demográfica. A los problemas evidentes en muchos casos de falta de recursos y de mejor accesibilidad, habría que añadir muchos más ámbitos en los que actuar: la vivienda, la política educativa, la normativa ambiental, agrícola y ganadera, y también los bienes comunales.

La importancia histórica de la formación y mantenimiento de bienes comunales como sustento de numerosas comunidades rurales es una cuestión frecuentemente olvidada por la historiografía contemporánea y por la política actual. Muy pocos trabajos se han encargado de demostrar la importancia de los comunales y de su crisis a la hora de explicar la crisis del medio rural. Sin duda, uno de los trabajos que más ha incidido en esta cuestión es el libro de Dardot y Laval (2015), en especial a la hora de relatar la historia de la privatización de bienes comunales, desde los famosos enclosures desde el siglo XVIII hasta el ciclo del agua en la actualidad en multitud de países.

En el caso español, Algarra va aún más allá cuando afirma que en la historiografía catalana "no hay rastro de poder político popular, ni trabajo comunitario, ni ayuda mutua, ni bienes comunales" (ALGARRA BASCÓN, 2015: 25). Para este autor, en los libros de la ESO solo se muestra la historia y el patrimonio construido para las élites, mientras que no hay rastro de la historia ni del amplio y variado abanico de patrimonio popular (ALGARRA BASCÓN, 2015: 21). Muchos de estos bienes comunales en forma de edificios, dehesas, huertas y bosques fueron el sustento básico de multitud de comunidades rurales en toda la Península Ibérica. Su proceso de privatización paulatino, sobre todo a partir de las desamortizaciones, confundiendo estas propiedades con otras de la iglesia o de la aristocracia, sin duda debió de tener un efecto en el abandono de cientos de comunidades. La puntilla a esta política de privatizaciones vino de la mano de la política de repoblaciones forestales del franquismo. Éstas se realizaron tras la compra-venta de fincas forestales, pero muchas de ellas provenían de desamortizaciones previas que incorporaban monte comunal, y en otros casos se produjeron expropiaciones forzosas de terrenos cuya titularidad no quedaba clara, hecho frecuente en muchos montes comunales (GÓMEZ MENDOZA; MATA OLMO, 1992: 45). 
No obstante, la política de cercamientos de antiguas propiedades comunales ha seguido casi hasta la actualidad, dificultando, cuando no prohibiendo directamente, actividades tradicionales como la ganadería ovina. Así relata un pastor vasco la situación en el caserío de Bernagoitia, en el municipio de Amorebieta-Etxano:

"Últimamente la diputación está vallando [el monte], pese a ser del común, para plantar árboles. Subió Crispín a vigilar sus ovejas una tarde y las halló amontonadas y confundidas al encontrar cegados los pasos habituales, esos que ellas tan bien conocen. Cerradura por aquí, cerradura por allá, no tenían ni agua las pobres" (GANCEDO, 2015: 215).

La cita con la que se inicia este trabajo es un extracto del Catastro del Marqués de la Ensenada, en el que se detalla minuciosamente la enorme variedad de propiedades y bienes comunales de que disponía la población de Ciria, uno de tantos municipios sorianos que han perdido en las últimas décadas gran parte de su población. Muchos de los edificios y recursos que se enumera aquí son hoy en día edificios en ruinas, en desuso o que pasaron a formar parte de propiedades privadas, aunque puedan ser considerados o estén protegidos como patrimonio. Poco queda en la actualidad de esta larga relación de propiedades, que fueron durante siglos, a veces con mejor o peor fortuna, construidos y mantenidos por el pueblo de Ciria.

\section{OBJETIVOS Y METODOLOGÍA DE ESTUDIO}

El objetivo de este trabajo es por lo tanto analizar la importancia de los bienes comunales en el medio rural, y particularmente en la construcción y producción de diferentes espacios, hoy en día patrimonializados por su importancia histórica, cultural o religiosa. En segundo lugar, se pretende mostrar que los bienes comunales, además de ser formas de relación social del pasado, pueden ser herramientas útiles en cualquier estrategia de revitalización de espacios rurales en declive, sobre todo a partir de la puesta en marcha de proyectos de custodia patrimonial colectiva en antiguas propiedades del común hoy en día en desuso o abandonadas.

Se trata de dos objetivos muy ambiciosos para llevar a cabo en el poco espacio que contiene un artículo de investigación, lo que obliga o bien a trabajar en el plano teórico desde generalizaciones, o bien a descender al caso práctico. Ambos casos suponen un riesgo alto de simplificación, pero el segundo caso puede ser quizás más ilustrativo y claro para el lector o la lectora, dado que la cuestión de los bienes comunales es aún hoy en día poco conocida. En este caso se opta por mostrar la importancia de los bienes comunales en el mundo masovero, en concreto en una aldea del turolense municipio de San Agustín, Mas Blanco. 
Las reflexiones que siguen a continuación no se han obtenido aplicando una metodología de investigación ortodoxa cuantitativa o cualitativa, sino más bien son fruto de un trabajo etnográfico del autor durante cinco años de la mano de la asociación de investigación-acción Recartografías, que durante este periodo de tiempo ha trabajado en la restauración de diferentes bienes comunales de Mas Blanco. La observación directa, la consulta del archivo municipal y la recopilación de numerosos testimonios de masoveros que habitaron este barrio, constituyen los elementos en los que se basa esta investigación que aún sigue en curso en la actualidad, a medida que se va recopilando más información sobre este lugar. Uno de los problemas principales a la hora de realizar cualquier investigación sobre la cultura masovera es que se trata de una sociedad sin apenas registros escritos sobre su historia, tradiciones y costumbres. Gran parte de esta cultura, desde leyendas, tradiciones gastronómicas, hechos históricos o conocimientos sobre agricultura, pastoreo o construcción, se trasmitía de padres a hijos. A esto hay que añadir que el archivo municipal de San Agustín fue saqueado e incendiado en la Guerra Civil española, por lo que las únicas fuentes importantes para conocer la historia de una masada como Mas Blanco es a través del testimonio de antiguos masoveros.

\section{EL HÁBITAT DISPERSO DE LA MASÍA. EL CASO DE MAS BLANCO}

El hábitat disperso, en el caso de Aragón, se divide en tres modalidades, cuya característica común es que constituyen unidades de explotación agraria con un centro de gestión, que es la vivienda, y una inequívoca presencia en el paisaje: la pardina, la torre y la masía, mas o masada (RUIZ BUDRÍA; FRUTOS MEJÍAS, 2014). La singularidad del mas o la masía es que integra en una misma parcela usos agro-silvo-pastorales según la aptitud del terrazgo, la casa y las dependencias funcionales en un coto redondo (RUIZ BUDRÍA; FRUTOS MEJÍAS, 2014: 476). El modelo de gestión dominante en la masía era la medianería: el propietario entregaba tierras, vivienda y ganado al masovero, participando ambos de gastos y beneficios al 50\% (HERNÁNDEZ, 2008: 96). Su carácter disperso se explica porque resuelve históricamente el problema de las distancias entre los núcleos urbanos y las tierras de labor, ordenando el territorio y el paisaje. Este carácter disperso hace que el territorio de las sociedades masoveras, entre las sierras orientales turolenses, el interior de la provincia de Castellón, gran parte de Catalunya y de las Islas Baleares, posea un riquísimo y variado patrimonio arquitectónico, en muchos casos en peligro por la desaparición de este modo de vida.

La peculiaridad de Mas Blanco es que no se trata de una única masía, sino de una agrupación de viviendas que forman un núcleo masovero con diversas calles y eras. Este fenómeno de agregación de masías es muy poco fre- 
cuente, y solo suele darse en el sur de la provincia de Teruel. El origen de Mas Blanco es seguramente moderno. No hay ninguna constancia documental de su fundación y, según los antiguos vecinos y vecinas, comenzó siendo una primera masía en un altozano, a la que se fueron agregando nuevas construcciones. Según apunta Madoz, a mediados del siglo XIX, había en el término de San Agustín "hasta 40 casas de campo o masadas en que habitan los colonos todo el año" (MADOZ, 1849). Seguramente fue a mediados del siglo XIX, tras las guerras carlistas y motivados por el aumento poblacional ligado a la transición demográfica, cuando se construyeron numerosas masías en nuevos terrenos roturados como es el caso de Mas Blanco. La razón fundamental por la cual no es hasta esta época cuando no se desarrolla un poblamiento masovero importante en esta zona es la escasez de fuentes de agua, condición indispensable para la vida en un hábitat disperso. Según relatan algunos vecinos, algunas de las masías aún hoy existentes datan de esta época. Por lo tanto, la masada de Mas Blanco se caracteriza por su arquitectura popular moderna, pero utilizando materiales y técnicas de construcción tradicionales: muros de piedra, forjados de vigas de madera y bovedilla de mortero, y cubiertas a dos aguas con teja árabe sobre cañizo.

A principios del siglo XX, Mas Blanco ya es una de las masadas más importantes del municipio de San Agustín. En 1911 se publican los primeros mapas topográficos de la zona, donde se aprecia el núcleo de Mas Blanco, junto con otras masías cercanas como El Tarín o Casa Antona. Justo en esta época se constituye aquí la "Sociedad Humanitaria", concretamente en 1919. Se trata de una sociedad de ayuda mutua entre masoveros, para socorrerse en caso de enfermedad, viudedad o accidente, un interesante precedente a la Seguridad Social y los seguros. No existe referencia alguna sobre esta sociedad, o parecidas en otras masías de Teruel, lo que refuerza la tesis de Algarra (2015) de cómo la historia de las comunidades rurales y sus costumbres de ayuda mutua y autogestión ha sido en muchas ocasiones invisibilizada. La peculiaridad del caso de Mas Blanco es que los masoveros decidieron hace un siglo institucionalizar sus costumbres de ayuda mutua mediante la redacción ante notario de unos estatutos. La lectura de este documento, así como de las sucesivas asambleas que se celebraron entre 1919 y finales de los años 60, cuando esta sociedad dejó de funcionar por el éxodo rural, da cuenta de la importancia de los bienes comunales en la vida de Mas Blanco.

Pocos años después, las familias masoveras decidieron construir un primer edificio comunitario, el cubo o almacén y bodega. Una de las actividades agrícolas en Mas Blanco era la viticultura. Según cuentan algunos antiguos vecinos y algunas vecinas, la vendimia era una actividad comunitaria que se realizaba entre varias familias, aunque las vides fuesen una propiedad privada. Al carecer el barrio de una bodega, se decidió edificar frente a una de las eras y aprovechando un desnivel un edificio con prensa de madera y

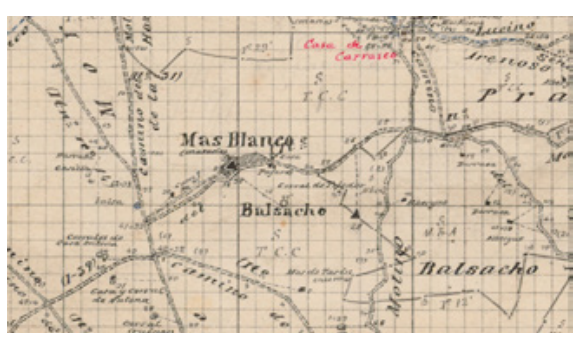

Detalle del plano geométrico de San Agustín de 1911 | plano Centro Nacional de Información Geográfica (CNIG), 2019

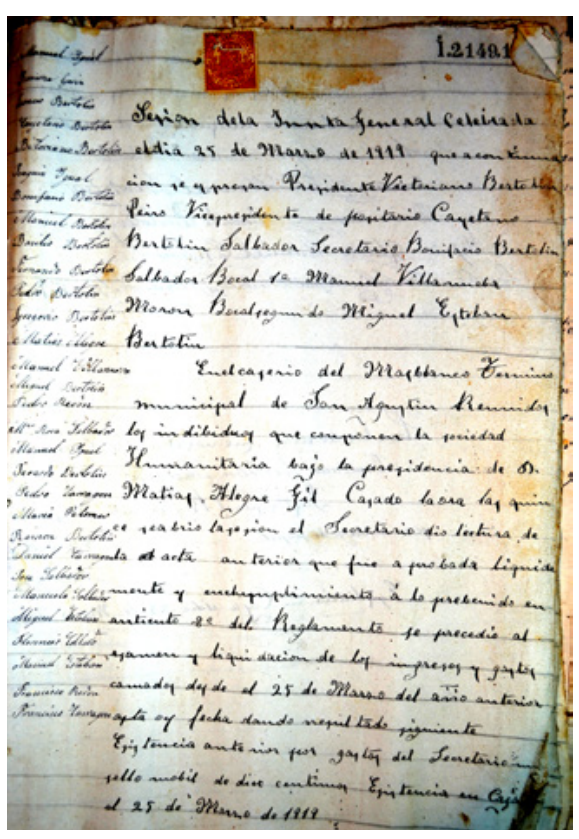

Acta de constitución de la "Sociedad La Humanitaria" de Mas Blanco de 1919 | fuente Museo de las Masías y la Memoria Rural de Mas Blanco 


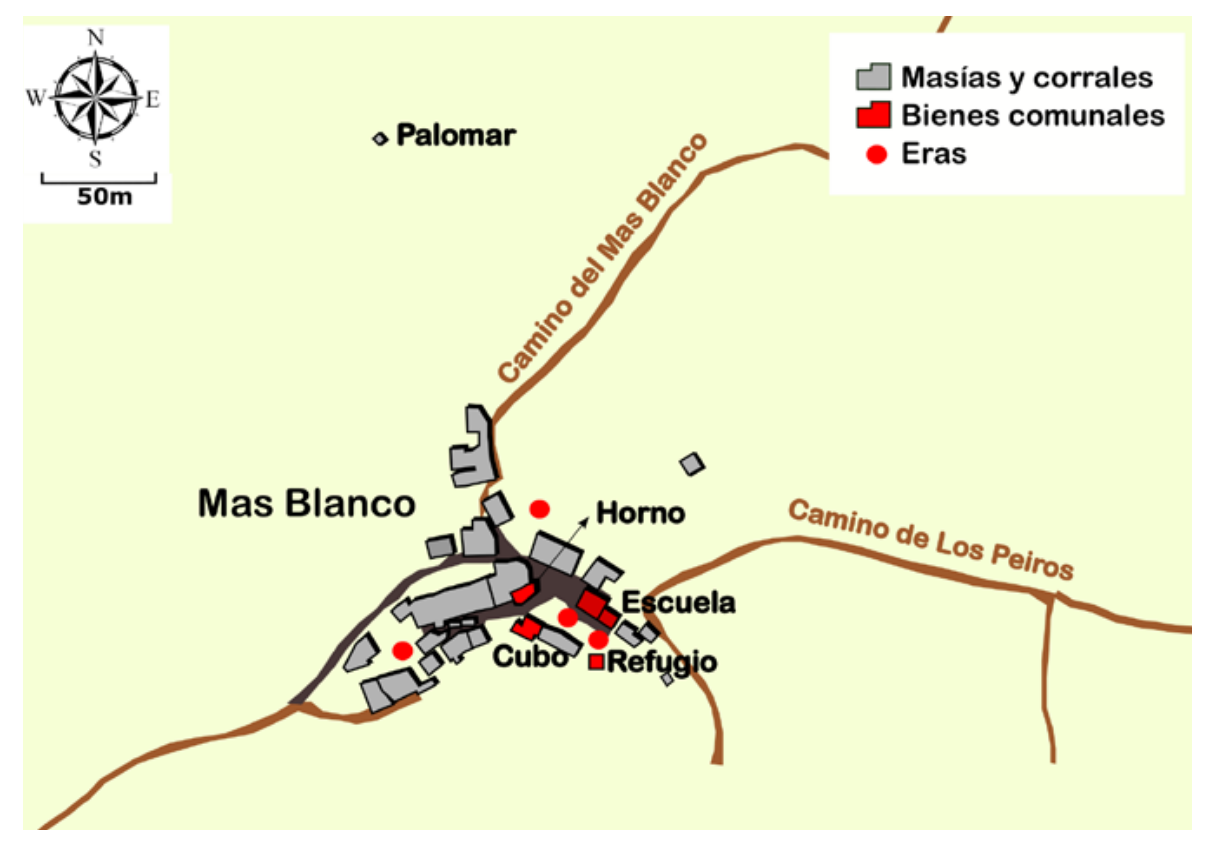

cubo de más de cinco metros de profundidad, donde se chafaba la vid y se dejada fermentar. Al final del proceso, cada familia recibía en vino la cantidad proporcional a la vid aportada. Además de la viticultura, las otras dos actividades principales eran la agricultura cerealística y la ganadería ovina. Los bienes comunales tuvieron un protagonismo importante para su desarrollo. En el caso de la producción de cereales, aunque los campos eran casi siempre propiedades privadas, varias eras de Mas Blanco y del término eran bienes comunales, y muchas veces el trillado y aventado se realizaba entre varias familias. La ganadería ovina se desarrolló gracias a que muy cerca de Mas Blanco discurre una importante vía de trashumancia, para conectar la sierra de Gúdar con las llanuras del Mediterráneo. A lo largo de esta ruta y desde la Edad Media, los pastores gozaban de ciertos privilegios de derrota de mieses y derechos de paso y de pasto en propiedades privadas. A esto hay que añadir que gran parte del término de San Agustín era terreno forestal y pastos comunales.

La Guerra Civil fue casi tan traumática para el mundo masovero como la posguerra con la guerrilla del maquis, cuando por orden gubernamental numerosas masías fueron desalojadas por la Guardia Civil (HERNÁNDEZ, 2008). En el caso de Mas Blanco, ante los continuos bombardeos de la aviación italiana, los vecinos se movilizaron para construir un refugio antiaéreo debajo de una era, otro ejemplo más de ayuda mutua que da como resultado un equipamiento que no financia ninguna administración pública o privada. Tras la guerra, los masoveros de Mas Blanco y de muchas masadas vecinas vivieron unos años de auténtico terror, por los continuos enfrenta- 


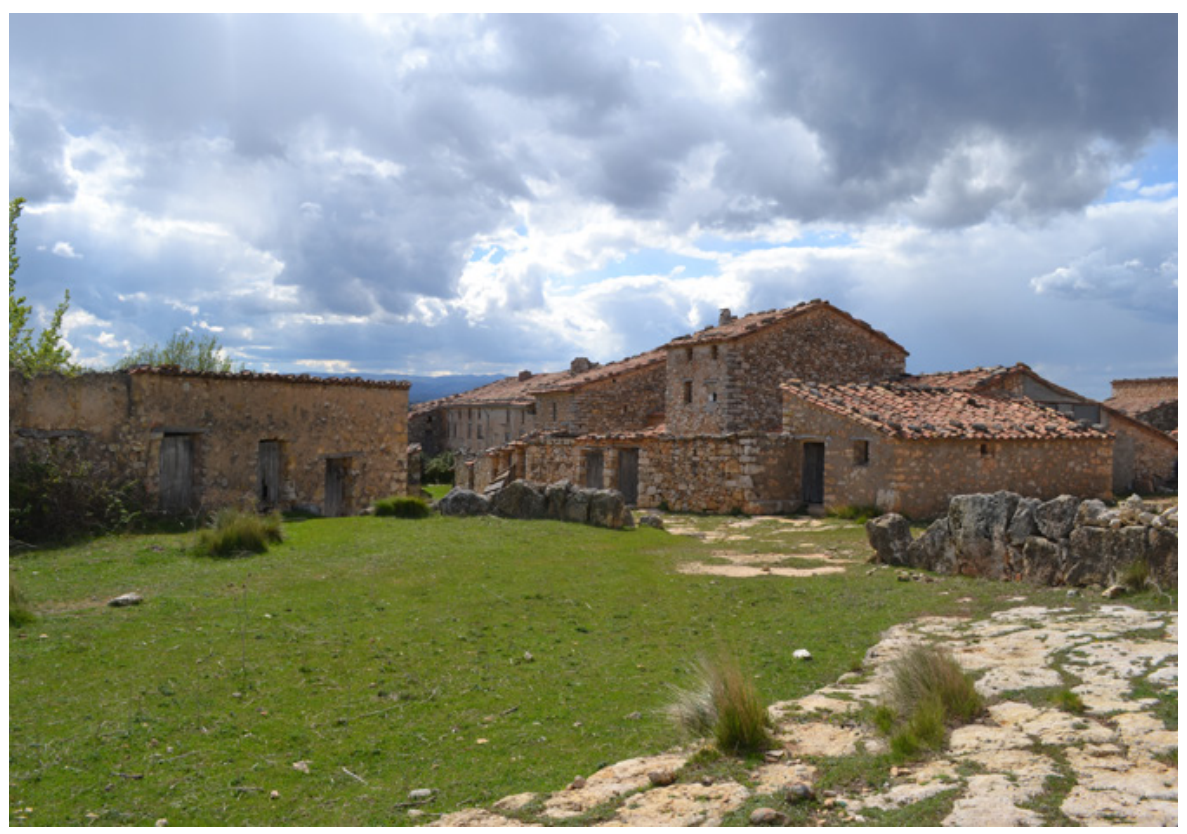

mientos entre la Guardia Civil y la guerrilla del maquis, lo que obligó a situar varios destacamentos de la Guardia Civil en varios puntos del municipio. En este contexto de inseguridad, desde la Sociedad La Humanitaria se decide emprender la construcción de otro bien comunal: una escuela mixta. De esta manera los hijos y las hijas de los masoveros dispondrían de un aula escolar sin tener que recorrer largos y peligrosos caminos. Todos los vecinos recalcan que esta escuela, y la casa de la maestra construida pocos años después, fue completamente realizada con los esfuerzos y recursos de los masoveros, sin que el Gobierno Civil de turno aportase nada. Este nuevo bien comunal fue inaugurado finalmente en 1950, y la casa de la maestra cuatro años después. Aunque se trata de dos edificios modernos, su interés patrimonial radica en que se trata de dos muestras de arquitectura popular tradicional y funcional, con materiales poco habituales en esas fechas como el sillarejo, la cubierta de vigas de chopo y el falso techo fabricado con cañizo del cercano río Mijares.

La escuela funcionó desde 1950 hasta 1973, cuando se ordenó el cierre de todas las escuelas rurales de la provincia con pocos estudiantes, y la concentración del alumnado en escuelas-hogar como la de Teruel. Se trata de un ataque más a los bienes comunales, en este caso directo, ordenando el cese de la actividad, aunque según relatan los vecinos aún había en esos años en torno a cinco estudiantes. A partir de ese momento, la escuela y la casa de la maestra, otro bien comunal más, quedaron abandonadas y con los años fueron convertidas en corrales de ganado, acelerando aún más su degradación.
Edificio del cubo a la izquierda y horno a la derecha, con cubierta a un agua | foto Luis del Romero Renau 
Aún contó Mas Blanco con otro bien comunal más: un horno, también construido por distintas familias. También la cocción del pan era una actividad comunitaria. Cada familia por turno debía de ocuparse una vez por semana de encender el horno y caldearlo para que alcanzase la temperatura adecuada. Seguidamente, la misma familia encargada de encender traía de casa su masa preparada y la trabajaba hasta formar panes de distinto tamaño. Tras su horneado, otra familia repetía la misma operación. El horno tenía la capacidad de hornear decenas de panes para todas las familias del barrio en una época, a mediados del siglo XX, en la que esta masada llegó a tener casi un centenar de habitantes.

En total, esta pequeña comunidad llegó a contar con cuatro edificios comunales, un refugio, varias eras y centenares de hectáreas de pasto y bosque de quejigo comunal para explotar sus leñas. En todo este relato de la evolución de Mas Blanco, no se ha mencionado en ningún momento la acción de la administración pública o de la Iglesia. En efecto, estas dos fuertes instituciones en fechas tan recientes como mediados del siglo XX están prácticamente ausentes del mundo masovero de Mas Blanco. La religiosidad del mundo masovero se mostraba en numerosas festividades o bureos que se celebraban a lo largo del año en diferentes masías, y en la festividad de la virgen de Pradas. La iglesia parroquial de San Agustín tenía un papel secundario, pese a sus tentativas de controlar la vida de toda la población del término. Similar situación sucedía con la administración local, con una relación que se podría caracterizar como extractivista o pasiva, en palabras de García (2016). Los únicos contactos de este hábitat disperso con las admi-

Aspecto de la escuela de Mas Blanco en 2012, antes de su rehabilitación | foto Luis del Romero Renau

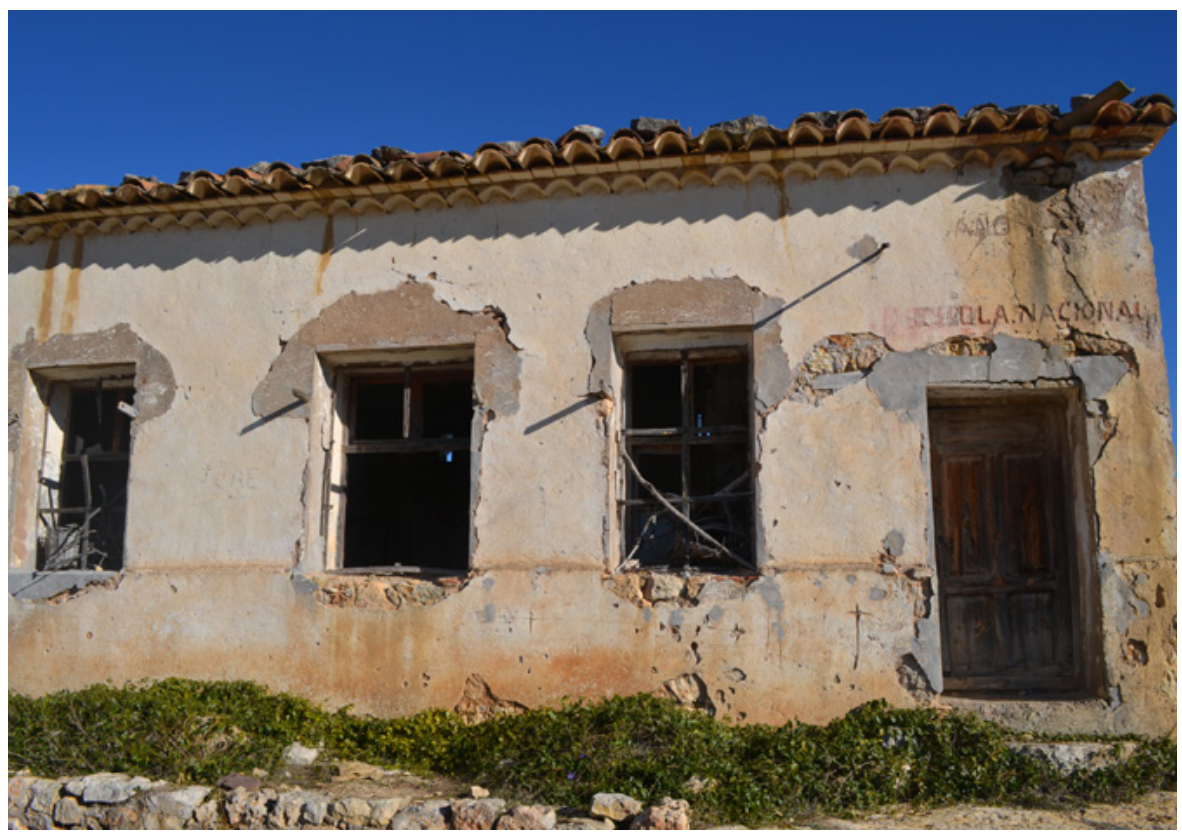


nistraciones públicas eran con el cobrador de impuestos, los inspectores de diversas administraciones agrícolas como el Servicio Nacional del Trigo, la Guardia Civil y el bando para el reclutamiento obligatorio, con el fin último de percibir rentas o fuerza de trabajo de la población masovera que a cambio no recibía nada.

Quizás habría que profundizar en el estudio de esta relación como una de las causas principales del éxodo de las masías como Mas Blanco, y no tanto en explicaciones basadas en la falta de infraestructuras o servicios y en la falta de viabilidad de la actividad agroganadera. No en vano, Mas Blanco siempre dispuso de una buena accesibilidad por la cercanía de la carretera nacional Sagunto-Burgos y de una línea de tren de Zaragoza a Valencia con una estación a escasos kilómetros. Si bien es cierto que la atención médica era una carencia importante, no fue así con la educación por la disponibilidad de escuela hasta 1973. Sea como fuere, y al igual que sucedió con gran parte de las áreas rurales del país, a partir de los años 70 Mas Blanco desciende drásticamente de población hasta quedar a partir de la década siguiente tan solo una familia viviendo en esta aldea, mientras que decenas de masadas vecinas son abandonadas.

\section{ACTIVISMO CIUDADANO PARA LA CUSTODIA PATRIMONIAL: EL CASO DE RECARTOGRAFÍAS}

A principios del siglo XXI la masada de Mas Blanco era uno de tantos núcleos casi abandonados de la provincia de Teruel. Tan solo resistía el matrimonio formado por Ascensión y Eusebio, que abandonó finalmente la masada en 2004 por problemas de salud de este último, aunque en esos años comenzó a arreglar una de las casas un matrimonio británico. El conjunto de bienes comunales que habían pertenecido a los masoveros de Mas Blanco fueron escriturados a nombre del Ayuntamiento, pasando a ser así de una propiedad comunal a una municipal, lo que generó un importante descontento entre los antiguos vecinos y vecinas. Pese a este cambio de propietario, que suponía en la práctica la abolición de buena parte de los bienes comunales de la masada, no se emprendió ninguna acción para su restauración o conservación, con lo que el proceso de degradación continuó imparable afectando a las cubiertas de la escuela y la casa de la maestra, hasta el punto de que parte de los edificios amenazaban ruina.

La situación global del municipio de San Agustín no era mucho mejor. En 2001 la población empadronada se reducía a 127 habitantes, sesenta menos que una década anterior (ESTADíSTICA, 2019). En Mas Blanco tan solo quedaban un par de habitantes, mientras que muchas otras masías y barrios habían quedado completamente vacíos. La crisis económica que estalló en 2007, sin embargo, cambió la situación radicalmente. Varios vecinos oriun- 
dos de San Agustín pero residentes en Catalunya se quedaron sin empleo, y encontraron aquí un refugio imprescindible en momentos de gran vulnerabilidad social. Este retorno de familias tuvo un efecto inmediato en la demografía: en 2007 la población empadronada subió hasta los 165 habitantes, y durante algunos años posteriores llegó a los 200 habitantes.

En este contexto de declive rural contenido temporalmente surgió el colectivo Recartografías entre varios geógrafos y geógrafas de la Universitat de València que llevaban años trabajando en el problema de la despoblación del medio rural en Aragón y Comunidad Valenciana. El proceso de despoblación había llegado a ser tan intenso, que más que de éxodo convenía comenzar a hablar de vaciamiento demográfico. La ausencia casi total de población y actividad durante años en amplias zonas de montaña valencianas y aragonesas tuvo un impacto hasta en la toponimia de los mapas topográficos, que en las últimas ediciones dejaba de ubicar muchos antiguos topónimos, o bien los localizaba erróneamente, como era el caso de Mas Blanco (DEL ROMERO RENAU; VALERA LOZANO, 2013). El objetivo que se planteó este colectivo, posteriormente convertido en asociación cultural, fue la puesta en marcha de un proyecto de rehabilitación de un núcleo rural abandonado o deshabitado. Tras un estudio exhaustivo del fenómeno del abandono de pueblos en la provincia de Teruel, junto con algunos limítrofes con Castellón (DEL ROMERO RENAU; VALERA LOZANO, 2013), se decidió iniciarlo en el municipio de San Agustín.

Se planteó un proyecto de rehabilitación con dos novedades importantes: que partiera desde el activismo ciudadano y con fórmulas de gestión innovadoras. En primer lugar, fueron personas no vinculadas personalmente con Mas Blanco quienes emprendieron el proyecto de rehabilitación sostenible del conjunto de bienes comunales con que contaba Mas Blanco, comenzando con la escuela. Se trató de un proyecto que surgió desde la sociedad civil, aunque desde el principio recibió el apoyo del Ayuntamiento y de antiguos y nuevos vecinos y vecinas, que se animaron a colaborar en la primera fase de restauración de la escuela. La selección de este edificio no fue casualidad. La escuela suele identificarse en nuestra memoria como un lugar de recuerdos de niñez y de formación de la persona, con lo que suele haber una mayor sensibilidad por la preservación de este tipo de edificios. Además, desde el inicio Recartografías decidió trabajar solamente en los antiguos bienes comunales que había pertenecido a los masoveros de Mas Blanco. Seguramente por esta razón, una de las claves del éxito en este proyecto fue la buena sintonía tanto con el Ayuntamiento, como con los antiguos masoveros desde el inicio.

En segundo lugar, la buena acogida de un proyecto de rehabilitación por parte de un grupo de personas ajenas al municipio se debió al clima de cambio y apertura social que estaba experimentando San Agustín en esos años 
de crisis. El alcalde en el momento de iniciarse el proyecto había nacido y vivido en Barcelona durante décadas, al igual que pasaría con los dos siguientes alcaldes que ha tenido el municipio. En Mas Blanco hacía pocos años que se había instalado una familia británica, y en otro barrio o aldea del municipio, en Los Poviles, hizo lo propio una familia alemana, mientras que una joven pareja valenciana puso en marcha un negocio de casas rurales en otra aldea más del municipio, y otra comenzaba a hacerse cargo del bar. Estas llegadas, sin embargo, apenas compensaban las pérdidas demográficas del municipio, sobre todo por saldo natural negativo, y también por éxodo rural (ESTADÍSTICA, 2019). Al contrario de lo que podría haber sucedido en otros municipios, en San Agustín no hubo conflicto entre nuevos y viejos residentes, por el consenso existente de necesidad de nuevos habitantes para sobrevivir como comunidad rural.

En tercer lugar, la fórmula de gestión del proyecto escogida fue la custodia del territorio. Se define esta modalidad de intervención como un conjunto de estrategias e instrumentos que pretenden implicar a las personas propietarias y usuarias del territorio en la conservación y el buen uso de los valores y los recursos naturales, culturales y paisajísticos. Para conseguirlo, promueve acuerdos y mecanismos de colaboración continua entre propietarios, entidades de custodia y otros agentes públicos y privados (BASORA ROCA; SABATÉ I ROTÉS, 2006). La asociación firmó un contrato de custodia del territorio con el Ayuntamiento de San Agustín por cinco años, con el compromiso por parte de la asociación de realizar una gestión responsable, y con el del Ayuntamiento de colaborar en la medida de lo posible, pero dejando claro que a partir de ese momento el usufructuario de los espacios comunales sería la asociación. A este acuerdo firmado en pleno municipal le siguió otro con la última habitante de la masada, que decidió ceder su masía, campos y corrales a la asociación con el mismo fin. La asociación pudo contar a lo largo de cinco años con personas voluntarias desinteresadas de diferentes perfiles, que contribuyeron a llevar el proyecto adelante. Hasta esta fecha, se han restaurado la escuela, la casa de la maestra, el horno comunal y el cubo, y se han realizado obras de mejora en caminos, dos masías y un corral con bodega. Estos espacios se convirtieron en marzo de 2019 en el Museo de las Masías y de la memoria rural, en el que se muestra la historia y causas de la decadencia y éxodo del mundo masovero (MUSEO, 2019), con la particularidad de que se trata de un museo al aire libre en una masada, en lugar de encontrarse en el centro de un pueblo o ciudad como suele ser habitual. Este proyecto se complementa con un plan de reactivación de espacios para ir más allá de la simple musealización: la escuela acoge regularmente seminarios y jornadas sobre el mundo masovero, y el horno, talleres de horneado tradicional recuperado por varias descendientes de masoveras.

Este activismo ciudadano ha ido mucho más allá de conseguir la rehabilitación de varios edificios en una pequeña aldea. El logro más importante es 
Escuela de Mas Blanco, tras su rehabilitación | foto Recartografías

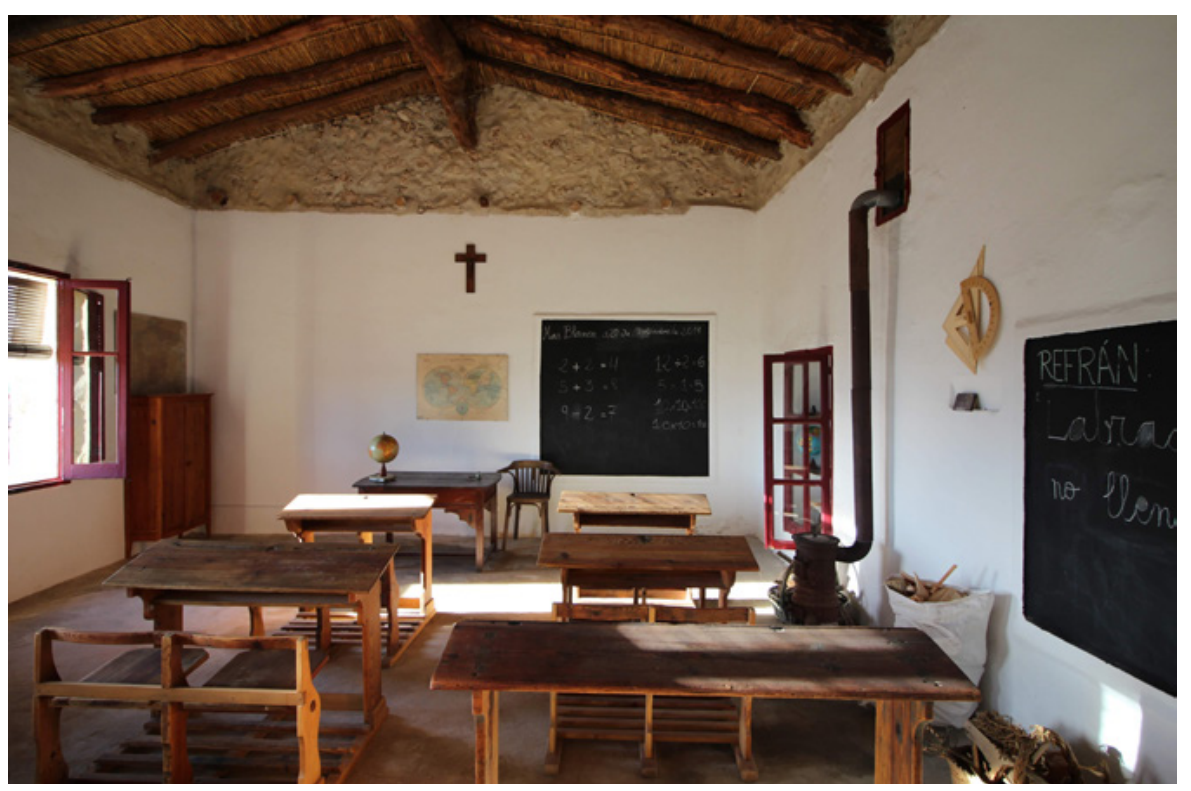

el cambio de percepción respecto a una aldea casi abandonada como Mas Blanco. La puesta en marcha de este proyecto, con la realización de numerosos campamentos, generó la ilusión necesaria en numerosos vecinos para regresar a su lugar de origen, y rehabilitar asimismo sus propias casas o bien ponerlas a la venta. Algunos de ellos, emigrantes en Barcelona, hacía años o incluso décadas que no habían vuelto a esta masada, aunque mantenían unos importantes vínculos con San Agustín, un ejemplo de lo que Gascón y Cañada (2018) denominan: "turismo de la diáspora". Poco después de iniciarse el proyecto, varias masías empezaron a ser rehabilitadas por particulares, lo que animó a su vez a otros propietarios a vender o intervenir en sus propiedades. En la actualidad, además de la familia británica residente todo el año, otras seis familias han comenzado a restaurar distintas masías y corrales del núcleo, manteniendo las características arquitectónicas tradicionales de la masía, y convirtiendo este espacio abandonado en un espacio vivo y de relaciones sociales, cuando en el mejor de los casos podría haberse convertido en una urbanización de veraneo. Tanto la escuela como el horno, antiguos bienes comunales, están siendo reapropiados y resignificados por la colectividad que en la actualidad reside en San Agustín o en Mas Blanco. Se consiguió evitar que la memoria de estos bienes cayese en el olvido y, después de su rehabilitación, vuelven a estar plenamente funcionales para su uso.

En definitiva, el caso de Recartografías y de la rehabilitación de los bienes comunales de Mas Blanco es un ejemplo de cómo la noción de patrimonio ha cambiado sustancialmente y los sentidos de autenticidad, materialidad y monumentalidad, en los cuales estaba basada, han perdido fuerza. Ahora, 


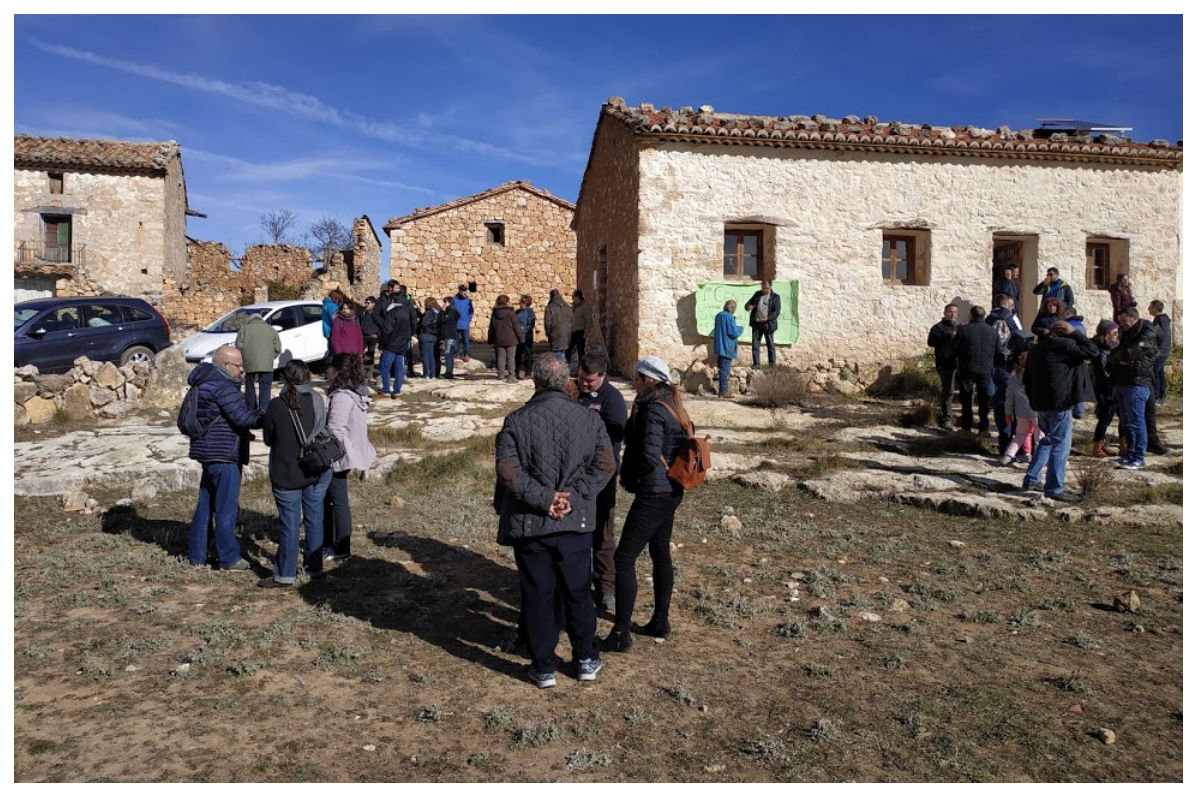

Jornada de inauguración del Museo de las Masías y de la Memoria Rural | foto Sara Gil

se empieza a reconocer, desde las instituciones, que la cultura es dinámica, que el patrimonio debe hablar a través de los valores que la gente le otorga y no al revés (NúÑEZ, 2013). Una de las funciones que ha adoptado Mas Blanco es la de museo, pero siguiendo el concepto latinoamericano de nueva museología comunitaria, en la que es una colectividad quien gestiona una serie de espacios, mientras que la exposición se convierte en espacio de creación y producción de conocimiento (NÚÑEZ, 2013). La recuperación de los bienes comunales no obedece simplemente a una acción de recuperación y patrimonialización de la memoria rural y de reivindicación de su importancia histórica, sino que debería convertirse en un elemento básico para cualquier estrategia de repoblación, por la potencialidad que presentan. Los bienes comunales deberían resignificarse como espacios de encuentro, de actividad, e incluso de vivienda, tal y como sucedió hasta hace poco tiempo, modernizando el concepto de medianería hacia fórmulas menos onerosas para las personas usufructuarias como la custodia del territorio.

\section{CONCLUSIONES}

Existe un amplio consenso político, social y mediático sobre la urgente necesidad de abordar con políticas integradas y coordinadas el problema de la despoblación en buena parte del interior peninsular. De no llevar a cabo un ambicioso programa de medidas para facilitar y dignificar la vida en el campo, el desierto demográfico que ya se extiende por buena parte de la Cordillera Ibérica no parará de crecer. Donde ya no existe un consenso tan 
claro es en el tipo de medidas a poner en marcha y en el reparto de responsabilidades. En esta discusión, uno de los recursos menos estudiados como causa de la despoblación, pero también como oportunidad para la dinamización territorial, son los bienes comunales.

Este conjunto de bienes fue durante siglos argamasa y podio de la práctica totalidad de las comunidades rurales que hubo en España en distintos momentos de la historia. El caso del mundo masovero, y concretamente de Mas Blanco en Teruel, no se entiende sin esas formas de ayuda mutua y gestión colectiva de bienes comunales. Además de la aristocracia, la monarquía o la iglesia, a lo largo de la historia el mundo masovero se caracterizó por un alto nivel de autogestión que fue rápidamente desarticulado, pero que estaba vigente hasta hace pocas décadas.

La recuperación física y simbólica de los bienes comunales, y su resignificación como nuevos espacios de actividad y de memoria, son los dos objetivos que a lo largo de cinco años puso en marcha la asociación Recartografías. Se trató de una iniciativa ciudadana, que consiguió concitar el apoyo del Ayuntamiento de San Agustín y de numerosos antiguos vecinos. Cinco años después de su inicio culminó con la apertura de un museo en la antigua masada de Mas Blanco dedicado al mundo masovero y al éxodo rural. Esta acción ha permitido cambiar la dinámica demográfica y del municipio, al menos en lo que se refiere a habitantes temporales, por la llegada de nuevas familias a la masada. Más allá del papel simbólico que tiene este hecho en un territorio en situación crítica, muestra cómo desde la acción ciudadana, y mediante fórmulas innovadoras como la custodia del territorio, se pueden dar importantes pasos hacia el objetivo común de que San Agustín y gran parte de Teruel y del interior peninsular no se conviertan en un gran vacío demográfico.

Por último, proyectos como el desarrollado en Mas Blanco muestran que abordar el problema de la despoblación pasa también por la adopción de un papel protagonista de la ciudadanía y que la escala del microproyecto puede tener efectos multiplicadores sobre territorios con muy poca población como es el caso de San Agustín. A menudo se piensa en grandes políticas para el abordaje del problema de la despoblación, como la extensión de infraestructuras y servicios, cuando en muchos casos, a través de pequeñas acciones se puede conseguir generar un clima de optimismo en una comunidad rural, que sea capaz de activar, si no dinámicas de atracción migratoria, de retorno de antiguos emigrantes, o de nuevas familias, por lo menos acciones de rescate patrimonial entre nuevos y antiguos residentes. En este sentido, el activismo ciudadano para la custodia territorial será clave en los próximos años para abordar la ingente tarea de conservar y salvaguardar el patrimonio que existe en miles de poblaciones abandonadas o con muy escasa y envejecida población. 


\section{BIBLIOGRAFÍA}

- ALGARRA BASCÓN, D. (2015) El comú català. La història dels que no surten a la història. Vilanova del Camí: Potlatch ediciones, 2015

- ACÍN FANLO, J. L. (2004) [dossier] La despoblación como cuestión científica y humana. Ripacurtia [en línea], n. ${ }^{\circ}$ 2, 2004, pp. 15-32 <https://www.raco.cat/index.php/ Ripacurtia/article/view/28716> [Consulta: 27/08/2019]

- AlARES lópeZ, G. (2010) El vivero eterno de la esencia española. Colonización y discurso agrarista en la España de Franco. En SABIO ALCUTÉN, A. (ed.) Colonos, territorio y Estado. Los pueblos del agua de Bardenas. Zaragoza: Institución Fernando el Católico (IFC), 2010, pp. 57-80

- BADAL, M. (2018) Vidas a la intemperie. Nostalgias y prejuicios sobre el mundo campesino. Logroño: Pepitas, 2018

- BASORA ROCA, X.; SABATÉ I ROTÉS, X. (2006) Custodia del territorio en la práctica. Manual de introducción a una nueva estrategia participativa de conservación de la naturaleza y el paisaje. Barcelona: Xarxa de Custodi del Territori y Fundació Territori i Paisatge, Caixa Catalunya, 2006 Disponible en <http://custodiaterritori.org/mm/xct castella_web.pdf> [Consulta: 27/08/2019]

- CAMPOS CACHO, S. (2018) La despoblación, desenfocada. Revista de Libros [en línea] 22 de enero de $2018<$ https://www.revistadelibros.com/resenas/la-despo blacion-desenfocada> [Consulta: 27/08/2019]

- CATASTRO de Ensenada (2017) [en línea] Portal de Archivos Españoles, Ministerio de Cultura <http:// pares.mcu.es/Catastro/servlets/ServletController? accion=2\&opcion=70> [Consulta: 27/05/2019]

- CERDÀ, P. (2017) Los últimos. Voces de la Laponia española. Logroño: Pepitas, 2017

- CERVERA, C. (2019) Los orígenes de la ruina que desangra a España desde el siglo XVI: la despoblación que obsesionó a Carlos III. ABC [en línea] <https://www.abc.es/ historia/abci-origenes-ruina-desangra-espana-desde-siglodespoblacion-obsesiono-carlos-201905030213_noticia. html> [Consulta: 28/05/2019]

- COllantes GUTIÉRREZ, F. (2004) El declive demográfico en la montaña española (1850-2000) ¿Un drama rural? Madrid: Ministerio de Agricultura, Pesca y Alimentación, 2004

- ESTADÍSTICA Local de Aragón. Ficha territorial de San Agustín (2019) [en línea] Instituto Aragonés de Estadística $<$ http://bonansa.aragon.es:81/iaest/fic_mun/pdf/44206. pdf> [Consulta 08/07/2019]

- GANCEDO, E. (2015) Palabras mayores. Logroño: Pepitas, 2015
- gARCíA MARTíneZ, A. (2016) Alabanza de aldea. Gijón: KRK Editorial, 2016

- GASCÓN, J.; CAÑADA, E. (2018) Turismo en el mundo rural. Soberanía Alimentaria [en línea], n. ${ }^{\circ} 32,8$ de septiembre de $2018<$ https://www.soberaniaalimentaria. info/numeros-publicados/63-numero-32/556-turismo-en-elmundo-rural> [Consulta: 08/07/2019]

- GÓMEZ BENITO, C. (2004) Una revisión y una reflexión sobre la política de colonización agraria en la España de Franco. Historia del presente, n. ${ }^{0} 3,2004$, pp. 6586. Disponible en <http://historiadelpresente.es/revista/ historia-presente/20041> [Consulta: 27/08/2019]

- GÓMEZ MENDOZA, J.; MATA OLMO, R. (1992) Actuaciones forestales públicas desde 1940. Objetivos, criterios y resultados. Agricultura y Sociedad, n. ${ }^{\circ} 65,1992$, pp. 15-64

- HERNÁNDEZ SESÉ, A. (2008) El mas turolense. Crisis de un modelo de población. Estudis d'història agraria [en línea], n. ${ }^{\circ}$ 21, 2008, pp. 89-104 <https://www.raco.cat/ index.php/EHA/article/view/183491/236210> [Consulta: 27/08/2019]

- LAVAL, C.; DARDOT, P. (2015) Común. Ensayo sobre la revolución del siglo XXI. Madrid: Gedisa, 2015

- LÓPEZ PALOMEQUE, F.; FELIP FILLAT, R. A.; TULLA, A.; SORIANO, J. M. (1996) Revitalització de pobles abandonats del Pirineu. Barcelona: Generalitat de Catalunya, 1996

- LÓPEZ ANDRADA, A. (2017) El viento derruido: La España rural que se desvanece. Córdoba: Almuzara, 2017

- OSWALT, P. (ed.) (2006) Shrinking cities: volume 2. Interventions. Ostfildern, Hatje Cantz Verlag, 2006

- MADOZ, P. (1849) Diccionario geográfico estadístico de España y sus posesiones de ultramar, vol. XIII. Est. tip. de P. Madoz y L. Sagasti, 1849

- MARSDEN, T. (1995) Beyondagriculture? Regulating the new rural spaces. Journal of Rural Studies, vol. 11, n. ${ }^{\circ}$ 3, 1995, pp. 285-296

- MOLINO, S. (DEL) (2016) La España vacía. Viaje por un país que nunca fue. Madrid: Noema, 2016

- MONTSERRAT, P.; VILLAR, L. (1999) Consecuencias ecológicas del abandono de tierras y de la despoblación rural. Forest Systems [en línea], vol. 8, n. ${ }^{\circ} 3$, 1999, pp. 135141 <https://recyt.fecyt.es/index.php//A/article/view/2764> [Consulta: 27/08/2019]

- MUSEO de las masías y de la memoria rural (2019) Recartografías [en línea] <http://recartografias.es/museo/> [Consulta: 29/05/2019] 
- NÚÑEZ, A. (2013) Resignificaciones y reapropiaciones del patrimonio cultural. Baukara, n. ${ }^{\circ} 4,2013$, pp. 6-21

- PERRIER-CORNET, P. (dir.) (2003) Repenser les campagnes. París: Datar. Editions de l'Aube, 2003

- PLANO geométrico por términos municipales mandado formar por la Ley de 27 de marzo de 1900. Provincia de Teruel, término municipal de San Agustín (2019) Centro Nacional de Información Geográfica (CNIG) Centro de descargas en línea <http://centrodedescargas.cnig.es/ CentroDescargas/index.jsp> [Consulta: 29/05/2019]

- ROMERO RENAU, L. (DEL) (2018) Despoblación y abandono de la España rural: el imposible vencido. Valencia: Tirant Humanidades, 2018

- ROMERO RENAU, L. DEL; VALERA LOZANO, A. (2013) Territorios abandonados. Paisajes y pueblos olvidados de Teruel. Teruel: Instituto de Estudios Turolenses y CEDDAR, 2013

- RUIZ BUDRÍA, E.; FRUTOS MEJÍAS, L. M. (2014) Los "mases", elementos fundamentales en la estructura del paisaje turolense oriental. En ARNÁEZ VADILLO, J.; GONZÁLEZ SAMPÉRIZ, P.; LASANTA MARTÍNEZ, T.; VALERO GARCÉS, B. L. Geoecología, cambio ambiental y paisaje: homenaje al profesor José María García Ruiz. Logroño: Consejo Superior de Investigaciones Científicas, CSIC, Instituto Pirenaico de Ecología, Universidad de La Rioja, 2014, pp. 471-479 
